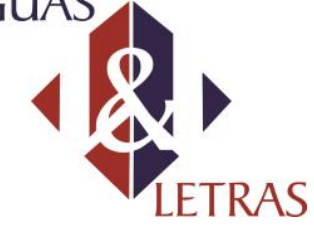

\title{
Desmontado a Juana de Ibarbourou y de América'
}

\author{
Desmontado a Juana de Ibarbourou de América
}

Carmen Luna Sellés*

*Universidade de Vigo/Espanha, e-mail: carmenluna64@gmail.com

\begin{abstract}
RESUMEN: Juana Fernández Morales, conocida universalmente como Juana de América, escritora uruguaya, considerada una de las voces más personales de la lírica hispanoamericana de principios del siglo XX, adoptó el apellido de su marido para firmar sus publicaciones, dejó de ser Juana Fernández para convertirse en Juana de Ibarbourou. Ella aceptó esos dos nombres derivados del discurso de lo femenino que elaboró la lógica patriarcal de la época, y esa aceptación invisibilizó durante mucho tiempo resistencias discursivas presentes en su obra que a todas luces se muestran enfrentadas a esa codificación. En este artículo pretendo desmontar la sumisión feliz de la amante-esposa (Juana de Ibarbourou) y de la poeta nacional (Juana de América) que el campo cultural le asignó.

PALABRAS-CLAVE: Juana Fernández Morales; estrategia discursiva; disidencias.
\end{abstract}

RESUMO: Juana Fernández Morales, conhecida universalmente como Juana de América, escritora uruguaya, considerada uma das vozes mais singulares da lírica hispanoamericana dos principios do século XX, adotou o sobrenome de seu marido para assinar suas publicações, deixou de ser Juana Fernández para ser Juana de Ibarbourou. Ela aceitou esses dois nomes derivados do discurso do femenino que elabora a lógica patriarcal da época, e essa aceitação tornou invizível, durante muito, tempo resistencias discursivas presentes em sua obra. Neste artigo pretendo questionar a imagen de submissão feliz da amante-esposa (Juana de Ibarbourou) e da poeta nacional (Juana de América) atribuída a ela no campo cultural.

PALAVRAS-CHAVE: Juana Fernández Morales; estrategia discursiva; dissidências.

\footnotetext{
${ }^{1}$ Esta artículo, efectuadas diversos cambios y actualizaciones, fue previamente publicado en SAN ROMÁN (coord.). Os vínculos culturais Galicia-Uruguay. José Alonso y Trelles / Juana de Ibarbourou. Lugo: Fundación Comarcal A Mariña Central/Fundación Comarcal A Mariña Oriental, 2010 .
} 


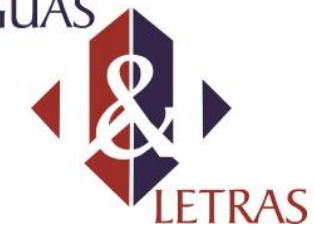

DOI: $10.5935 / 1981-4755.20160003$

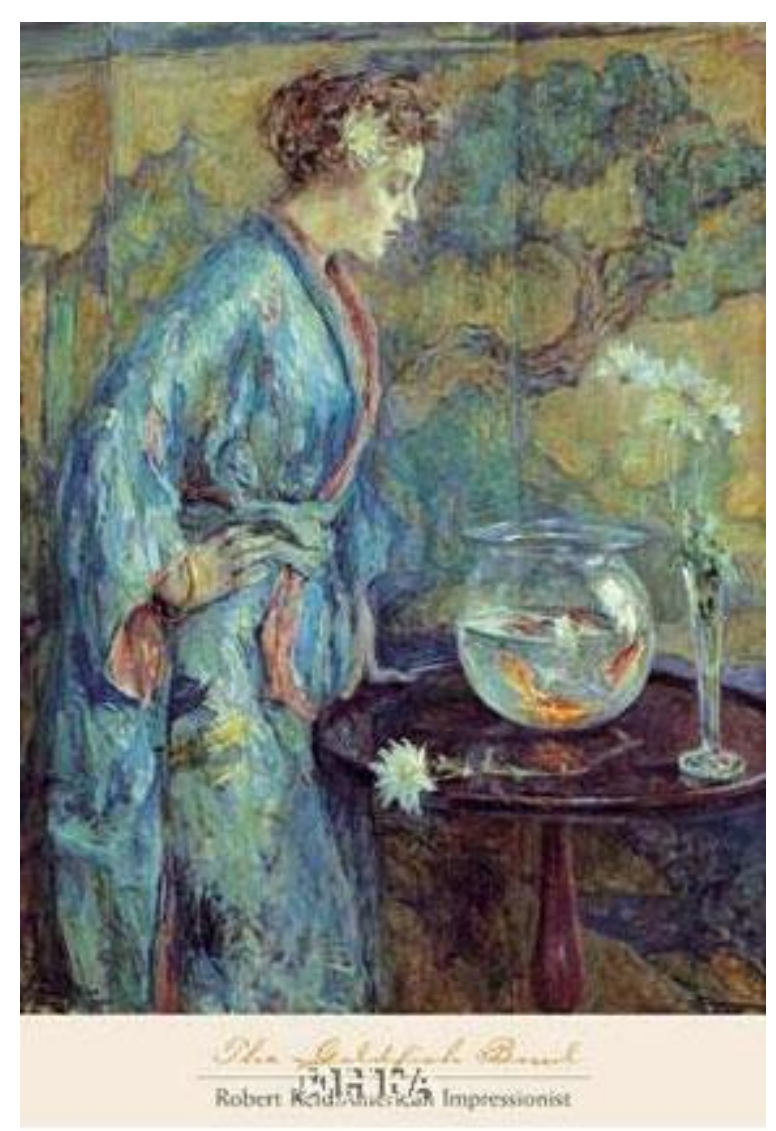

Como es bien sabido Juana Fernández Morales adoptó el apellido de su marido para firmar sus publicaciones ${ }^{2}$, dejó de ser Juana Fernández para convertirse en Juana de Ibarbourou. Y la intelectualidad uruguaya, aún cercana la celebración estatal batllista del Centenario (1925) de la declaración de la Independencia, con Juan Zorrilla de San Martín a la cabeza y con la presencia del escritor mejicano Alfonso Reyes, la proclama, el 10 de agosto de 1929 en el Salón de los "Pasos Perdidos" del Palacio Legislativo, "Juana de América"3. Ella aceptó esos dos nombres derivados del discurso de lo femenino ${ }^{4}$ que elaboró la lógica patriarcal de la época, y esa aceptación invisibilizó durante mucho tiempo resistencias discursivas presentes en su obra que a todas luces se muestran enfrentadas a esa codificación. En este artículo pretendo desmontar la

\footnotetext{
2 También usó el pseudónimo "Jeanette d'Tbar" en sus primeros poemas publicados en la prensa uruguaya, principalmente en La Razón.

${ }^{3}$ Aunque el acto de proclamación de "Juana de América" no fue iniciativa del Estado uruguayo sino de un grupo de estudiantes, el hecho de celebrarse en el Palacio Legislativo, inaugurado en 1925 para celebrar el Centenario de la independencia, provocó que la ceremonia y la figura social de Juana quedara asociada al poder público.

${ }^{4}$ Seguimos la terminología de Aralia LÓPEZ-GONZÁLEZ en su artículo Justificación teórica: fundamentos feministas para la crítica literaria (1995, pp. 19-24) en el que señala que frente al discurso de lo femenino que elabora la lógica patriarcal surgen discursos femeninos (la mujer hablada y pensada por la mujer) y/o feministas que son expresión de una contra-Razón.
} 
sumisión feliz de la amante-esposa (Juana de Ibarbourou) y de la poeta nacional (Juana de América) que el campo cultural le asignó ${ }^{5}$.

Una imagen que de forma gráfica podría definir y expresar el contenido fundamental del discurso poético (la estrategia discursiva) de Juana de Ibarbourou es el cuadro de Robert Reid (1862-1929) titulado “Muchacha con Kimono azul” de 1911. En él, una hermosa joven situada en un espacio interior y vestida con un kimono, que apenas se distingue de la decoración del panel del fondo, observa con melancolía cómo dan vueltas unos peces en una pequeña y redonda pecera situada en una mesa también redonda. Como primera interpretación podríamos pensar que se trata de un interior burgués, donde la mujer es vista como un objeto más de ese espacio -de hecho su ropa exótica se confunde con el decorado del exótico biombo-. Espejo de los pensamientos de su marido, mientras ésta contempla el agua encerrada en la pecera circular, podríamos decir -parafraseando las palabras de Bram Dijkstra (1994, p. 183) ante la descripción de este cuadro- que esta mujer seguramente no era vista a principios de siglo -época de realización del cuadro- como algo distinto a los peces que nadan en círculo, sin sentido. Ella ¿no era otro pez más? No nos puede sorprender, por tanto, la actitud contemplativa, melancólica y triste de la expresión de la mujer, tan bien captada por este pintor.

En cierta medida cuando nos acercamos a la vida y obra de Juana y a cómo fue y es leída, percibimos que hay una gran semejanza con esta composición gráfica. La poeta Juana de Ibarbourou y su poesía formaron parte del decorado intelectual y social de la época; éste se apropió de su poesía y de su cuerpo leyéndolo exquisito, delicado, primitivo, puro, inocente, sin fisuras ni resistencias, sin disonancias con respecto al discurso androcéntrico dominante. Ella exteriormente se vistió el kimono, se dejó confundir con el decorado de la época, pero en su particular y aburguesada pecera ella se sabe, se ve, atrapada, como los peces de colores que inútilmente dan vueltas, de ahí la visión -como la de la mujer del cuadro- melancólica, contemplativa y triste de su poesía, cuando no discordante, angustiosa: "Parece que mi vida presente fuera un pozo, / una angosta cisterna profunda y circular" [...] / La sombra es tan ceñida, tan honda es la cisterna, / que en mí no ha de dar nunca la mirada de Dios” (“La cisterna”, Las

\footnotetext{
${ }^{5}$ Para una mayor comprensión del éxito de la crítica que la consagró en 1929 como Juana de América es recomendable la lectura del artículo de María Inés TORRES Una poeta para América: hipótesis de lectura sobre la obra de Juana de Ibarbourou en la década de 1920 (2013, pp. 202-216).
} 
lenguas de diamante $^{6}$ ); visión ésta deliberadamente acallada, no visualizada, silenciada en su época por la crítica y curiosamente perpetuada hasta la nuestra. ¿No es suficientemente representativa la siguiente autorrepresentación, doblemente crítica e irónica, que Juana lleva a cabo en su, a simple vista, "inocente" poema "La niña boba" de Raíz salvaje (1922), que en cierta medida nos recuerda a la muchacha del cuadro de Reid?:

Las manos sobre la falda,

La mirada, al fuego, recta.

Haciendo "la niña boba"

Mientras los demás conversan.

$\mathrm{Y}$ un bienestar infinito

Soñando, soñando quieta. (pp. 213-14)

Juana sabe que no puede escapar de la sociedad burguesa y adopta una máscara de "niña boba", mientras en silencio ejercita la propia salvación que significa la personal obra literaria.

Yo supe de Juana de Ibarbourou, como muchos españoles interesados en la literatura latinoamericana, antes que por la propia lectura de su poesía por referencias críticas que destacaban su atrevido erotismo, siempre matizado con adjetivos de pureza y castidad, y que ubicaban su figura al lado de esa magnifica promoción de mujeres hispanoamericanas que comenzaban a hacerse oír en la década de los años veinte ${ }^{7}$, diferenciándola de ellas su conformismo, su adaptación a una vida social y familiar burguesa, sin disidencias, sobre todo porque su vida de casada fue aparentemente feliz y se vio realizada a través de la maternidad. Todo lo más que se apreciaba fuera de estos parámetros era el giro formal y temático dado en su producción poética a partir fundamentalmente de Perdida (1950), que apareció después de veinte años de silencio poético. Pero la fama lograda, principalmente a través de su primer libro Las lenguas de diamante (1919), las lecturas que generó por parte de sus compañeros masculinos de prestigio en el ámbito hispánico y la apropiación oficial que se hizo de su persona -que alcanzó su cenit con la proclamación de "Juana de América" el 10 de agosto de 1929

\footnotetext{
${ }^{6}$ IBARBOUROU, Juana de. Las lenguas de diamante. Raíz salvaje, ed. de Jorge Rodríguez Padrón, Madrid: Cátedra, 1998, p. 209. A partir de ahora siempre que realicemos citas de estos poemarios remitimos a esta edición.

${ }^{7}$ Es en esta segunda etapa de la modernidad hispanoamericana que Grinor ROJO en "El ensayo y Latinoamérica" (1998) denomina "la primera transformación de nuestra modernidad (1920-1950" cuando
} 


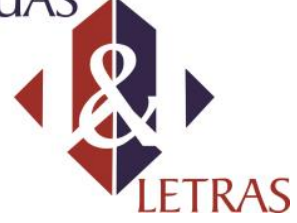

(cuando tan sólo había publicado dos poemarios y un libro en prosa) en el Palacio Legislativo presidido por Juan Zorrilla de San Martín y de la mano de Alfonso Reyes, como mencionamos al principio de este artículo, hizo que toda su producción posterior se unificara bajo las características asignadas a este primer poemario. ${ }^{8} \mathrm{Su}$ apropiación oficial $^{9}$ - como señala José Rodríguez Padrón- condicionó su lectura, pues se le aceptó como:

[...] representante de una poesía conservadora con la cual aquella burguesía capitalina podría de nuevo respirar tranquila, sintiéndose regalada con el sentimentalismo sin fisuras ni disidencias que añoraba. Y si alguna existía, se apresuraron a disfrazarla con apreciaciones tergiversadoras muy oportunistas; y poco después con el encumbramiento oficial que acabará legándonos una imagen equivocada de la poeta y alterando el verdadero sentido de su obra. ${ }^{10}$

Porque una atenta y no condicionada lectura de su obra muestra que, si bien Juana de Ibarbourou no se enfrentó al código moral dominante tan radicalmente como algunos de sus contemporáneos, por ejemplo, Julio Herrera y Reissig, Delmira Agustini o María Eugenia Vaz Ferreira, sí que hay en su poesía huella de confrontación y protesta; no sólo hay en ella, como se ha querido, vitalismo feliz y triunfante. Y pese a que aceptó el aburguesamiento del sistema, al mismo tiempo hay en su obra, desde sus comienzos, la conciencia de ser y estar al margen. Esa bipolaridad fue su drama nunca resuelto; la esencia de su poética, que está siempre presente en su obra y que muchos no quisieron o no pudieron ver. ${ }^{11}$ Se trata de un dualismo contradictorio, caracterizador, por otra parte, de los poetas modernistas. De forma reiterativa la crítica insiste en

por primera vez surge un grupo de mujeres con voz propia en el terreno de la producción textual; mujeres como Alfonsina Storni, Gabriela Mistral, Teresa de la Parra, Victoria Ocampo, entre otras.

${ }^{8}$ Tenemos que recordar que el acto oficial y multitudinario en el que se le proclamó "Juana de América" consistió en el casamiento literal -con anillo y novia vestida de blanco- de Juana con América. La alianza simbólica que la esposaba con todo un continente fue puesta en su dedo por Zorrilla de San Martín. (Russell, Dora Isella, "Nota biográfica", Obras completas, Juana de Ibarbourou, Madrid, Aguilar, 1960: XLIII)

${ }^{9}$ Un valioso estudio de la apropiación oficial que hizo de Juana de Ibarbourou, "Juana de América" es "Con sed de revolución: cuando las mujeres toman la palabra" de Estela Valverde, en Taller de Letras (Santiago de Chile: Instituto de Letras, Pontificia Universidad Católica de Chile), núm. 39 (2006), pp. 7388. Son interesantes las siguientes palabras que se refieren al nombramiento de "Juana de América": "Lo tangible de este episodio fue que a través de este acto el resto del mundo intelectual puso los ojos finalmente en Montevideo, en este Palacio Legislativo que quería erigirse en un centro ejemplar de constitución y gobierno. La mirada internacional confirmaba no tanto a Juana como la mejor poeta latinoamericana, sino a Uruguay como un país culto y exquisito que veneraba a sus artistas y los alzaba a categorías de realeza intelectual. A través de Juana de América, Uruguay ejercía su poderío intelectual continental, se hacía visible y sustancial. [...] A falta de reina creamos una esfinge poética que llevaba encapsulada todos los significantes que esta nueva sociedad necesitaba: prestigio y reconocimiento intelectual, belleza corporal, feminidad, buen gusto, elegancia europea." (pp. 76-77)

10 “Introducción” a Lenguas de diamante. Raíz salvaje (Madrid: Cátedra, 1998), pp. 27-28. 


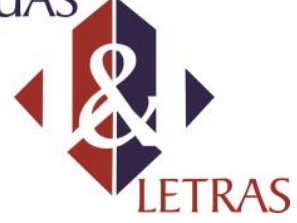

contraponer la poesía primera de Juana de Ibarbourou a la poesía de Vaz Ferreira y Agustini, señalando como elemento diferenciador la infelicidad manifiesta de estas últimas. Y esta valoración se justifica apelando a criterios extraliterarios como su vida ordenada y su realizada maternidad -como anteriormente señalábamos-, puesto que a las otras poetas señaladas se les había negado todo eso... ${ }^{12}$

Una lectura libre de todas estas propuestas críticas, desde nuestro punto de vista prejuiciadas, nos permite observar con claridad que su poesía no sólo es manifestación de vitalismo puro y triunfante, sin fisuras ni aristas, ni su situación personal tan idílica y domesticada como se quiso mostrar. Junto al vitalismo, al erotismo con calificativos paliativos, como "río de frescura", "fuerza tremenda de la naturaleza"; junto a la "castísima desnudez espiritual" de que hablaba Unamuno ${ }^{13}$, no se quiso y aún no se quiere ver en la poesía de Juana, desde su primer libro, que en muchas ocasiones expresa también una disidencia con respecto a la posición que como mujer le asignó la sociedad, o el discurso patriarcal. ${ }^{14}$ Es en este sentido que podemos decir que su escritura es autobiográfica, no en tanto que registra sucesos biográficos sino en cuanto que nos habla de las razones de una existencia de mujer en el seno de una sociedad concreta como la uruguaya de principios de siglo XX.

El discurso poético de Juana de Ibarbourou es el cauce donde el yo-mujer expresa su experiencia presente o pasada y da rienda suelta a la memoria para desvelar relaciones sexuales, encuentros y abandonos. Esta escritura autobiográfica es un espacio que alberga la reivindicación, expresa la sexualidad femenina y se presenta como única alternativa válida para sobrevivir a la desintegración emocional y personal, a la enfermedad y la muerte. Eso es lo que fue para Juana la poesía. ${ }^{15}$ La cursilería o el

\footnotetext{
11 Interesante pensamiento al que hace referencia a pie de página Jorge Rodríguez Padrón en su "Introducción" a la citada edición de Cátedra, p. 27, nota 24.

${ }^{12}$ Entre otros críticos que efectúan esta valoración podemos citar a Giuseppe Bellini en Figure della lirica femminile hispanoamericana (Milán: La Goliardica, Edizione Universitarie, 1975).

${ }^{13}$ En una carta personal fechada el 18 de septiembre de 1919 y reproducida por Jorge Arbeleche, "La generación del 98 y la literatura uruguaya", Boletín de la Academia de Letras, núm. 4, julio-diciembre 1998. Texto digitalizado: www.mec.gub.uy/academiadeletras/MarcoPrincipal.htm

14 En esta etapa, en el espacio discursivo de la crítica literaria, las mujeres poetas dejaron de ser "invisibles" a condición de que fueran portadoras de una serie de codificaciones del discurso moderno, que las situaba en el lugar de un "otro", consustanciado por el cuerpo, la naturaleza, la irracionalidad y el espacio doméstico-privado. La poesía de Juana fue "visible" pero bajo una óptica y una perspectiva androcéntrica que la constriñó. Esto es lo que reflejan las siguientes palabras de Alberto Zum Felde: "Juana de Ibarbourou, es, en cambio, lo más alejado que puede concebirse del tipo intelectual: es una intuitiva, más aún, una instintiva. Su cultura es escasa; y, felizmente para ella, porque no los necesita, ha leído pocos libros" (Proceso intelectual del Uruguay [Montevideo: Imprenta Nacional Colorada, 1930], Tomo III, p. 64).

${ }^{15}$ Para María Teresa Aedo (1996, p. 47) la poesía de Juana de Ibarbourou conforma un discurso que crea un sujeto que es un objeto para sí misma."
} 


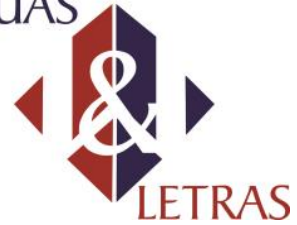

paternalismo de la época quería verla como la perfecta casada - con su marido (Juana de Ibarbourou) y con América (Juana de América) -, de ahí que en ocasiones se perciba la sorpresa, como en la carta personal de Miguel de Unamuno fechada el 18 de septiembre de 1919:

Una mujer, una novia, aquí, no escribiría versos como los de usted, aunque se le vinieran a las mientes y si los escribía no los publicaría y menos después de haberse casado con el que se los inspiró. Y si una mujer aquí se sale de la hoja de parra de mistiquerías escribidoras es para caer en cosas ambiguas y malsanas. ${ }^{16}$

O que se defina su poesía mediante la utilización de términos como "pureza", "ingenuidad", "satisfacción vital", "delicadeza", "sano", "delicioso", “casto", como podemos ver, por ejemplo, en la siguiente descripción de Guillermo de Torre:

Del mismo modo, Juana de Ibarbourou, tan semejante a la anterior [Delmiri Agustini] por sus cantos hipersensuales de morena Sulamita, pero menos violenta y conturbada (así ha podido escribir sagazmente Díez-Canedo: "La Agustini es la sensualidad atormentada; la Ibarbourou es la sensualidad triunfadora"), llenos de un casto y delicioso impudor que purifica su desfogado sensualismo, cristaliza su plenitud amorosa en los conocidos versos de "La Hora". ${ }^{17}$

Similar argumentación es la que podemos observar en el "Prólogo" de Manuel

Gálvez a la primera edición de Las lenguas de diamante:

La amada de este libro habla con ingenuo y casto impudor -si es posible unir estas dos palabras- de su cuerpo moreno, de caricias ardientes, de deseos. Pero no contiene el volumen, sin embargo, verdadero sensualismo. Felizmente, carece de impureza, y la voluptuosidad es en él escasa. Todo está dicho con dignidad, noble y bellamente, y no creo que pueda despertar en ninguna alma pensamientos impuros. Las lenguas de diamante está a buena distancia de esos libros de versos repugnantemente sensuales, olientes a voluptuosidad de lenocinio, que solían aparecer hace algunos años. [...] Tampoco muestran refinamiento los versos de Juana de Ibarbourou, ni nada de enfermizo ni de psicológicamente complicado; hay en ellos demasiada salud física y moral, para todo esto. ${ }^{18}$

Es también de notar que se evite mencionar directamente - porque formaba parte del tabú establecido- el erotismo, sin calificativos atenuantes, de su poesía o se unifique

\footnotetext{
${ }^{16}$ Carta reproducida por Jorge Arbeleche en el citado artículo "La generación del 98 y la literatura uruguaya".

17 “Tres nuevas poetisas argentinas", Alfar, núm. 29 (1923). La cursiva es nuestra.

18 "Prólogo" reproducido en la edición de Fredo Arias de la Canal, Las lenguas de diamante. Juana de Ibarbourou. El protoidioma en la poesía de Juana de Ibarbourou, México, Frente de Afirmación hispánica, 1998, pp. 9-10. Las cursivas son nuestras.
} 


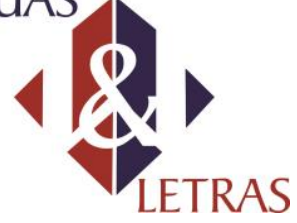

su discurso, como ya habíamos mencionado anteriormente, bajo un signo de optimismo y triunfo que de ninguna manera puede aceptar una lectura mínimamente atenta. ${ }^{19}$

Para comprender esto debemos entender los condicionamientos del momento, la estricta división social entre los papeles del hombre y de la mujer, los cuales, ante la emotividad y sensualidad sincera de Ibarbourou, se vieron en entredicho, y la mirada masculina, dominante, se obstinó en contemplarla como la feliz y virginal amante y esposa. Esta lectura, por ejemplo, queda cuestionada con la simple mención de algunos de los títulos de los poemas de sus dos primeros poemarios, que fueron los que le proporcionaron el reconocimiento oficial, y que son indicativos de sufrimiento, de vivencia problemática, de rebeldía y de dramática confrontación entre realidad y deseo: "La angustia del agua quieta", "Despecho", "Hastío", "Insomnio", “Inquietud”, "Hiel”, "Mujer", "La niña boba". Lo que no podemos aceptar es que la crítica académica actual siga manteniendo el argumento del vitalismo optimista sin fracturas como podemos observar en las dos siguientes citas de dos prestigiosos manuales (cursivas añadidas):

Eran libros signados por el modernismo [...] pero que traían un acento inédito a la poesía de la mujer: alegría de vivir y de amar, animada de vitalidad y sana sensualidad para cantar ardientes pasiones humanas. (GULLÓN, 1993, pp. 759-760)

[...] nada de grito erótico, alegría de vida esencial en la que ella se siente asumida por el cosmos. Amor natural ajeno a las sutilezas y complejidades de la civilización. ${ }^{20}$

Un complemento interesante de la visión de sus contemporáneos es que la propia Juana en su vida familiar y social aceptara una vida burguesa. Esto no significa que la actitud artística de Juana no tuviera mucho de rebelión contra una sociedad de valores burgueses; además, si lo observamos bien, su actitud es similar a la mantenida en el Fin de Siglo por sus coetáneos varones, que consistía en: si no se puede escapar de la sociedad burguesa y es imposible luchar en solitario contra ella, habrá que adoptar una

\footnotetext{
${ }^{19}$ Enrique DÍAZ-CANEDO tempranamente, en Dos poetisas de Uruguay. (Nosotros, núm. XLIII, 1923) inicia esta perspectiva: "La Ibarbourou es la sensualidad triunfadora". Aún hoy en día persiste esa visión como podemos comprobar en las siguientes palabras de una conocida página cultural en la web de la Secretaría Xeral de Emigración de la Xunta de Galicia que trata de recuperar los poetas hispanoamericanos de origen gallego: "A orixinalidade do seu estilo consistiu en unir o rico cromatismo con imáxenes modernistas, dándolle un sentido optimista da vida cunha linguaxe sinxela". Por su parte, Gastón BAQUERO hablando de Las lenguas... dice en Juana de América y de Ibarbourou: "Era un texto de pasión amorosa, pero de amor jubiloso, feliz, riente." (Quimera. Madrid, n. 123, 1994, p.16)

20 Giuseppe BELLINI, Figure della lirica femmenile hispanoamericana, edit. cit. Traducido y citado en Introducción de Jorge RODRÍGUEZ PADRÓN a IBARBOUROU, Juana. Las lenguas de diamante. Raíz salvaje. Madrid: Cátedra, 1998, p. 75.
} 
máscara de burgués y realizar en silencio la propia salvación a través de la personal obra literaria.

En este punto vuelvo al cuadro de Reid, "Muchacha con kimono azul". Tanto en él como a lo largo de toda la poesía de Juana, lo importante no es la expresión de satisfacción vital y gozo por la contemplación de la naturaleza, como una y otra vez escuchamos, sino la expresión de un sentimiento de clausura, de encierro, de estéril quietud, de inutilidad, como los peces de colores que inútilmente dan vueltas y vueltas y que devuelven en el reflejo del agua la propia imagen a la muchacha de kimono azul. Juana y la muchacha encerradas en un bello decorado, en un espacio doméstico/privado del que ambas son un objeto más, en un decorado plácido, en un espacio inmóvil pero (o por eso mismo) lejos de la acción, el riesgo, la aventura, en definitiva, fuera de la historia y el devenir, como bien lo expresa en su poema "Mujer" de Raíz salvaje:

\footnotetext{
Si yo fuera hombre, ¡qué hartazgo de luna,

De sombra y silencio me había de dar!

¡Cómo, noche a noche, solo ambularía por los campos quietos y por frente al mar!

Si yo fuera hombre, ¡qué extraño, qué loco Tenaz vagabundo que había de ser! ¡Amigo de todos los largos caminos que invitan a ir lejos para no volver!

Cuando así me acosan ansias andariegas

¡Qué pena tan honda me da ser mujer! (p. 211)
}

Lo que define toda su poesía es la confrontación entre realidad y deseo; es también la expresión del temor a que la realidad no permita la realización de sus deseos. Esto es lo que alegóricamente expresa en el poema "La estrella" de Las lenguas de diamante donde el yo poético se identifica con un loco y soñador pastor que pretende infructuosamente atrapar una estrella que se refleja en una charca:

Y yo, que asisto a la lección y llevo

En mi charca interior la dulce estrella

De una ilusión que se retrata en ella,

A ansiar la realidad ya no me atrevo.

Y como hipnotizada por el loco

Afán de no ver roto mi tesoro,

Hago guardia tenaz al astro de oro,

Lo miro fijo, pero no lo toco. (p. 108, cursivas añadidas)

Constantemente y a través de un lenguaje metafórico, Juana nos muestra su conflicto de mujer atrapada en la cotidianidad, deseosa de escapar de una quietud y un 


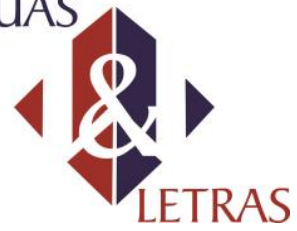

inmovilismo inútil. Quiere dejar de ser agua estancada o "arboleda inmóvil" para ser clamor ("inmenso alarido que ignoran los hombres" [p. 164]) y agua que corre, en definitiva, para tener voz y participar en el devenir -espacio que siente vedado-. La identificación con el agua es una de las autorepresentaciones más sobresalientes y constantes a lo largo de toda su obra poética. A través de esa identificación simbólica Juana expresa ese conflicto entre realidad y deseo. Su realidad, la realidad que rechaza, que no desea, es la que ata, la que constriñe, la que encierra sus ansias de libertad y no le deja participar en el acontecer, ni tener voz; por eso, ella que es agua, se identifica con "la angustia del agua quieta" (Las lenguas...) encerrada en un viejo pozo:

Parpado gris, inmóvil, con arrugas de piedra,
El brocal de este pozo viejo y abandonado,
Ostenta las pestañas de unos troncos de hiedra
Y la ceja herrumbrosa de un arco mutilado.
En el fondo, la oblea del agua muda y quieta
Es la pupila ciega de este pozo desierto.
¡Pupila siempre fija, por la angustia secreta
De la imagen inmóvil bajo el párpado abierto!

Aunque corran las nubes, aunque traigan los vientos

Pétalos de rosales y hojas de pensamientos,

Aunque pasen amantes coronados de hiedra,

Esta agua siempre fija, sin reflejos, tranquila,

En el fondo del pozo es la ciega pupila

Muda y desesperada en su cuenca de piedra. (p. 103)

Juana desea ser arroyo: "Besarás mil mujeres, más ninguna / te dará esta impresión de arroyo y selva" (“Olor frutal”, Raíz salvaje [p. 181]). Es fuente salvaje, pero se sabe atrapada, acallada: "Pero ahora estoy siempre taciturna y callada. / Poco queda de aquella chicuela de los campos, / cuya risa era viva como esos gajos de agua/ que se escapan del río a sisear por los pastos” (“Otoño”, Raíz salvaje [p. 212]) y se siente y se hermana con "El agua corriente" 21 , agua domesticada como ella. Por eso, para ella el mar es la libertad que añora y desea; el mismo mar que todos intuimos que añora "La muchacha con Kimono azul", como surgiere este poema, de título "Inmovilidad" tan poco ambiguo, de su segundo libro:

En la playa que el viento de otoño hace más sola

Noche a noche me siento frente a la tentación

De este mar que en sus ondas lleva y trae los navíos

\footnotetext{
${ }^{21}$ En el poema "El agua corriente" de Raíz salvaje dice: "Esta agua bullente / Que el grifo derrama, / Está henchida del hondo misterio / Del cauce del río, del viento y la grama" (p. 208).
} 


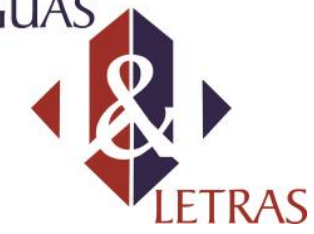

Que me envían, de lejos, su muda invitación.

Los veo hundirse en la niebla salpicados de luces.

Mundos breves y vivos que se echan a andar, En busca de horizontes distintos e imprevistos, Entre la hechicería de la luna y el mar.

Más allá...¡ Oh Dios mío, y yo aquí tan inmóvil Cual si fuera una piedra que nada ha de mover! ¡Ya me agobia el cansancio de soñar imposibles! ¡Ya se ha hecho espina mi ansia de tocar y de ver! (p. 191)

Es evidente que la obra de Juana de Ibarbourou está reclamando una lectura menos prejuiciada que la que hasta ahora se nos ha ofrecido; e incluso podríamos decir que está reclamando simplemente su lectura, pues la imagen que nos ha llegado de ella, fundamentalmente a través del canal institucionalista de manuales de literatura y de obras de divulgación, es la interpretación interesada de una época, acríticamente reutilizada a lo largo del tiempo, provocando un escaso interés por una autora y una obra que tal y como se nos muestra -fosilizada en una época y una poética ya superadaes poco atractiva para la crítica y los lectores actuales.

\section{REFERÊNCIAS}

AEDO FUENTES, María Teresa. Hablar y oír - saber y poder. La poesía de Juana de Ibarbourou desde Las lenguas de diamante hasta Mensajes del escriba. Revista Chilena de Literatura, Santiago de Chile, Universidad de Chile: Facultad de Filosofía y Humanidades, Departamentos de Literatura y Lingüística, n. 49, Nov., 1996, pp. 47-64. ARBELECHE, Jorge. Juana de Ibarbourou. Montevideo: Arca, 1978.

ARBELECHE, Jorge. La generación del 98 y la literatura uruguaya. Boletín de la Academia Nacional de Letras. Montevideo, Academia Nacional de Letras, Tercera Época, n. 4, Jul./Dic., 1998.

ARIAS DE LA CANAL, Fredo. Las lenguas de diamante. Juana de Ibarbourou. El protoidioma en la poesía de Juana de Ibarbourou. México: Frente de Afirmación Hispánica, 1998.

BAQUERO, Gastón. Juana de América y de Ibarbourou. Quimera, n. 123, 1994.

BELLINI, Giuseppe. Figure della lirica femminile ispanoamericana. Milán: La Goliardica, Edizione Universitarie, 1975.

DÍEZ-CANEDO, Enrique. Dos poetisas de Uruguay. Nosotros, Buenos Aires, n. XLIII, 1923.

DIJKSTRA, Bram. Ídolos de perversidad. La imagen de la mujer en la cultura de fin de siglo. Madrid: Debate, 1994.

GULLÓN, Ricardo. Diccionario de literatura española e hispanoamericana. Madrid: Alianza Editorial, 1993. 


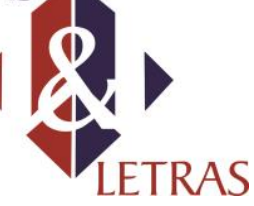

IBARBOUROU, Juana de. Las lenguas de diamante. Raíz salvaje. ed. De Jorge Rodríguez Padrón, Madrid: Cátedra, 1998.

LÓPEZ-GONZÁLEZ, Aralia, Justificación teórica: fundamentos feministas para la crítica literaria, en Aralia LÓPEZ-GONZÁLEZ (coord.), Sin imágenes falsas. Sin falsos espejos. Narradoras mexicanas del siglo XX. México: El Colegio de México, 1995.

MOLINA, César Antonio. La revista Alfar y la prensa literaria de su época (19201930). Coruña: Nós, 1984.

RODRÍGUEZ PADRÓN, Jorge. Introducción a IBARBOUROU, Juana. Las lenguas de diamante. Raíz salvaje. Madrid: Cátedra, 1998, pp. 15-117.

ROJO, Grinor. El ensayo y Latinoamérica. Revista de crítica cultural. Santiago de Chile, n. 16, junio, 1998. Separata: La vuelta de tuerca. Primer Congreso de Ensayistas Chilenos, Santiago, 13-14 de enero de 1998.

RUSSELL, Dora Isella. Notas biográficas. IBARBOUROU, Juana. Obras completas. Madrid: Aguilar, 1960.

TORRE, Guillermo de. Tres nuevas poetisas argentinas. Alfar, Coruña, Casa de GaliciaAmérica, n. 29, mayo, 1923.

TORRES, María Inés. Una poeta para América: hipótesis de lectura sobre la obra de Juana de Ibarbourou en la década de 1920. Cuadernos de Literatura, vol. XVII, n. 34, jul./dic., 2013, pp. 202-216.

VALVERDE, Estela. Con sed de revolución: cuando las mujeres toman la palabra. Taller de Letras, Santiago de Chile, Pontificia Universidad Católica de Chile, n. 39, 2006, pp. 73-88.

ZUM FELDE, Alberto. Proceso intelectual del Uruguay. Crítica de su literatura, Montevideo: Imprenta Nacional Colorada, 1930.

Data de recebimento: $28 / 11 / 2016$

Data de aprovação: 29/11/2016 